\title{
A HISTÓRIA E FILOSOFIA DA CIÊNCIA NO ENSINO DE FÍSICA: UMA ANÁLISE DAS PUBLICAÇÕES COM PROPOSTAS IMPLEMENTADAS EM
}

SALA DE AULA

\author{
HISTORY AND PHILOSOPHY OF SCIENCE IN THE TEACHING OF \\ PHYSICS: AN ANALYSIS OF PUBLICATIONS WITH PROPOSALS \\ IMPLEMENTED IN THE CLASSROOM
}

\author{
Carolina Model da Silva ${ }^{1}$ \\ Marcos Fernando Soares Alves ${ }^{2}$ \\ Henri Araujo Leboeuf ${ }^{3}$
}

\begin{abstract}
Resumo: A utilização da História e Filosofia da Ciência pode contribuir com o processo de ensino e aprendizagem de Física no contexto escolar e acadêmico. Entretanto, existem dificuldades à sua inserção em sala de aula, dentre eles, destacamos a carência de material educacional apropriado. Assim, neste trabalho, apresentamos os resultados de uma revisão bibliográfica que procurou analisar trabalhos publicados, entre 2011 e meados de 2018, em seis periódicos da área de Ensino que abordaram temas da Física e que tiveram como foco a implementação da História e Filosofia da Ciência em sala de aula. Em comparação com trabalhos anteriores, observamos um aumento nas publicações de resultados de intervenções didáticas envolvendo a Educação Básica. Além disso, ainda que haja uma centralidade no uso de textos, identificamos uma boa diversificação nos recursos didáticos utilizados e nos temas da Física abordados nas propostas.
\end{abstract}

Palavras-chave: História e Filosofia da Ciência; Intervenção didática; Recursos didáticos; Educação Básica.

\begin{abstract}
The utilization of History and Philosophy of Science may contribute to the process of teaching and learning of Physics in the school and academic context. However, there are difficulties to its insertion in the classroom, among those, there is a lack of appropriate education material. In this article, we present results of a bibliographic review that aimed at analysing published papers from 2011 to early 2018, in six scientific periodicals that would cover topics of Physics and would also focus on implementing History and Philosophy of Science in the classroom. When compared to previous papers, we observed an increase in publications of results of pedagogical interventions involving Basic Education. Furthermore, even though there is centrality in the utilization of texts, we identified a wide diversification in the utilized didactic resources and topics of Physics covered in the proposals.
\end{abstract}

Keywords: History and Philosophy of Science; Pedagogical intervention; Didactic resources; Basic Education.

\footnotetext{
${ }^{1}$ Licenciada em Física pelo Instituto Federal do Paraná (IFPR), campus Foz do Iguaçu, Paraná, Brasil. Email: carolinamodeldw@gmail.com

${ }^{2}$ Doutorando no Programa de Pós-Graduação em Educação para a Ciência e a Matemática da Universidade Estadual de Maringá (UEM). Professor de Física no Instituto Federal do Paraná (IFPR), campus Foz do Iguaçu, Paraná, Brasil. E-mail: marcos.soaresalves@gmail.com

${ }^{3}$ Mestre em Ensino de Ciências e Educação Matemática pela Universidade Estadual de Londrina (UEL). Professor de Física no Instituto Federal do Paraná (IFPR), campus Foz do Iguaçu, Paraná, Brasil. E-mail: henri.leboeuf@ifpr.edu.br
} 


\section{Introdução}

Na Física escolar, há ainda uma predominância do ensino tradicional com aulas expositivas e focadas na resolução de exercícios numéricos (BRASIL, 2002). Por isso, há diversas críticas para que, ao ensino da Física praticado nas escolas, sejam incorporados aspectos relativos aos resultados das pesquisas da área de Ensino.

No Ensino de Física, diversas abordagens curriculares e estratégias didáticas têm sido apontadas como auxiliadoras do processo de ensino e aprendizagem, tais como: atividades experimentais, Tecnologias da Informação e Comunicação (TICs), atividades investigativas, resolução de problemas, História e Filosofia da Ciência (HFC), entre outras. Entre tais possibilidades, destacamos a utilização da $\mathrm{HFC}^{4}$ como ferramenta de auxílio ao professor no processo de ensino, pois, conforme Martins (2007, p. 114), ela pode ser compreendida "[...] como estratégia didática facilitadora na compreensão de conceitos, modelos e teorias" (grifo do autor).

São inúmeros os argumentos favoráveis à utilização da HFC em sala de aula. Entre outros aspectos, é possível que a HFC propicie aos estudantes uma visão mais adequada sobre o fazer científico, torne as aulas mais motivadoras (MATTHEWS, 1995; MARTINS, 2006; MCCOMAS, 2013; HENKE; HÖTTECKE, 2015) e contribua para que compreendam a ciência como uma construção humana, sujeita a influências culturais, políticas e econômicas de uma época (MCCOMAS, 2013; MATTHEWS, 2015).

Quando realizada de maneira adequada, a abordagem de aspectos da HFC em sala de aula pode permitir que os alunos compreendam a ciência como uma construção coletiva e não como um processo isolado de um ou outro cientista (MATTHEWS, 1995; 2015; MARTINS, 2006; FERREIRA; MARTINS, 2012; FORATO; MARTINS; PIETROCOLA, 2012; HIDALGO; LORENCINI, Jr., 2016). Ela também é importante por contribuir na desmistificação da imagem social do cientista (MATTHEWS, 1988; MCCOMAS, 2013) e no entendimento de que a ciência está em constante transformação, não sendo, portanto, estática e nem realizada apenas por grandes gênios (MARTINS, 2006).

Ainda que a inserção da HFC no cotidiano escolar seja defendida por vários autores, existem muitos obstáculos a serem enfrentados pelos professores para que o seu

\footnotetext{
${ }^{4}$ Neste trabalho, não temos o propósito de distinguir a História da Ciência da Filosofia da Ciência; por isso, tomamos a liberdade, tal qual Martins (2007), de empregarmos o termo HFC ao conjunto de saberes por elas constituído.
} 
DOI: http://dx.doi.org/10.33238/ReBECEM.2019.v.3.n.3.23317

uso se torne uma realidade nas salas de aula. Entre os obstáculos, enfatizamos a falta de preparação dos professores (MARTINS, 2006; 2007; FORATO; PIETROCOLA; MARTINS, 2011; HÖTTECKE; SILVA, 2011; MCCOMAS, 2013; HENKE; HÖTTECKE, 2015), a falta de tempo dos professores em preparar aulas (MARTINS, 2007), o tempo didático para a execução da atividade (MARTINS, 2007; FORATO; PIETROCOLA; MARTINS, 2011), as dificuldades de leitura e interpretação de textos pelos alunos (MARTINS, 2007; FORATO; MARTINS; PIETROCOLA, 2012) e, ainda, a falta de materiais didáticos adequados e voltados à Educação Básica (MARTINS, 2006; 2007; FORATO; PIETROCOLA; MARTINS, 2011; HENKE; HÖTTECKE, 2015).

Para que os benefícios anteriormente apontados possam ser uma possibilidade no processo de ensino e aprendizagem de Física, é fundamental que as dificuldades impostas aos docentes sejam reduzidas. Neste aspecto, consideramos que a comunidade científica, os autores de livros didáticos e os cursos de formação de professores possuem um importante papel a ser desempenhado.

Desta forma, no presente estudo, objetivamos apresentar os resultados de um levantamento bibliográfico de trabalhos que se propõem a discutir propostas didáticas sobre HFC que tenham sido efetivamente implementadas em sala de aula e que tenham sido publicados nos principais periódicos nacionais de Ensino de Ciências e Ensino de Física. Nossa busca e análise se concentraram em seis periódicos e contemplaram os trabalhos publicados entre 2011 e meados de 2018.

Para nortear a escolha dos periódicos e a definição de alguns critérios de análise dos artigos selecionados, utilizamos as pesquisas desenvolvidas por Teixeira, Greca e Freire Jr. (2012) e Schirmer e Sauerwein (2014), por consideramos que tais estudos são complementares entre si e permitirem um comparativo com os resultados encontrados por nós. A seguir, apresentamos mais detalhes sobre os procedimentos metodológicos adotados.

\section{Abordagem Metodológica}

Na tentativa de realizarmos um levantamento bibliográfico e observarmos os avanços no uso da HFC em propostas implementadas em sala de aula, este trabalho, de cunho qualitativo e de revisão bibliográfica (COUTINHO, 2015), se apoia nos aspectos metodológicos das pesquisas realizadas por Teixeira, Greca e Freire Jr. (2012), que analisaram dados de 1980 até o primeiro semestre de 2011, e Schirmer e Sauerwein 


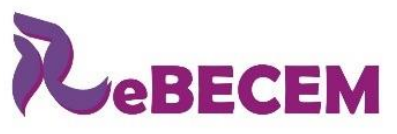

Revista Brasileira de Educação em

Ciências e Educação Matemática

DOI: http://dx.doi.org/10.33238/ReBECEM.2019.v.3.n.3.23317

(2014), que utilizaram informações de 2001 a 2010. Para tanto, realizamos um levantamento bibliográfico dos trabalhos publicados de 2011 a meados de 2018 nos mesmos periódicos nacionais de Ensino de Ciências e de Ensino de Física que foram analisados pelos autores citados.

Desta forma, os periódicos selecionados foram: Caderno Brasileiro de Ensino de Física (CBEF), Ciência \& Educação (C\&E), Ensaio: Pesquisa em Educação em Ciências (Ensaio), Investigações em Ensino de Ciências (IENCI), Revista Brasileira de Ensino de Física (RBEF) e Revista Brasileira de Pesquisa em Educação em Ciências (RBPEC). Exceto a revista Ensaio, investigada somente por Schirmer e Sauerwein (2014), todas foram objeto de análise dos pesquisadores mencionados. Além destas, Teixeira, Greca e Freire Jr. (2012) avaliaram também o periódico Enseñanza de las Ciencias que, apesar de elevada relevância para a área, optamos por excluí-lo ao definirmos analisar apenas periódicos e artigos em língua portuguesa.

Antes de iniciarmos o levantamento, na etapa de seleção dos artigos, estabelecemos os seguintes critérios de inclusão: a) seleção de trabalhos com propostas implementadas em sala de aula; b) que abordem temas relacionados à Física. Com base nestes critérios, o levantamento dos trabalhos foi realizado por meio da página eletrônica de cada um dos periódicos. No período delimitado, e após a exclusão dos artigos de outras áreas do conhecimento, averiguamos os trabalhos publicados em todos os números das revistas.

A seleção dos trabalhos foi realizada com base nos títulos, nas palavras-chave, nos resumos e, quando necessário, na leitura de outros elementos dos artigos a fim de determinar se continham propostas de HFC, com temas da Física, implementadas em sala de aula. Definido o corpus de análise, ou seja, o conjunto de artigos a serem analisados, todos os trabalhos foram lidos na íntegra e as informações pertinentes foram coletadas e tabuladas nas seguintes categorias: tema da Física abordado, nível educacional implementado, objetivos do trabalho, recursos didáticos utilizados e formas de uso dos recursos, papel do recurso didático, disponibilização pública do recurso, desenho da pesquisa (instrumentos de coleta de dados e metodologia da coleta), principais resultados, levantamento de conhecimentos prévios dos alunos e inconsistências, carências e dificuldades encontradas na implementação. Tais categorias foram criadas visando facilitar o diálogo com os resultados encontrados por Teixeira, Greca e Freire Jr. (2012) e Schirmer e Sauerwein (2014). 
DOI: http://dx.doi.org/10.33238/ReBECEM.2019.v.3.n.3.23317

\section{Resultados e discussões}

\subsection{Caracterização dos trabalhos selecionados}

Os artigos mostrados no Quadro 1 foram selecionados a partir dos periódicos analisados por Teixeira, Greca e Freire Jr. (2012) e Schirmer e Sauerwein (2014) e dos critérios de inclusão mencionados anteriormente. A referência completa dos trabalhos mostrados encontra-se nas Referências Bibliográficas.

Quadro 1: Resultado do levantamento de publicações com propostas de HFC implementadas em sala de aula

\begin{tabular}{|c|c|c|c|}
\hline Periódico & Qualis $^{5}$ & Artigos & Autores \\
\hline $\mathrm{CBEF}$ & A2 & 9 & $\begin{array}{l}\text { Rinaldi, Guerra (2011). Santos, Voelzke e Araújo (2012). Raposo } \\
\text { (2014). Silva e Moraes (2015). Reis e Reis (2016). Pinto, Silva e } \\
\text { Ferreira (2017). Bagdonas, Zanetic e Gurgel (2018). Hidalgo, } \\
\text { Schivani e Silva (2018). Vasconcelos e Forato (2018) }\end{array}$ \\
\hline $\mathrm{C} \& \mathrm{E}$ & A1 & 2 & Zanotello (2011). Rodrigues, Zimmermann e Hartmann (2012) \\
\hline Ensaio & A1 & 0 & - \\
\hline IENCI & $\mathrm{A} 2$ & 1 & Raicik e Peduzzi (2015) \\
\hline RBEF & A1 & 4 & $\begin{array}{c}\text { Silva, Santos e Dias (2011). Morais e Guerra (2013). Monteiro e } \\
\text { Martins (2015). Arthury e Terrazzan (2018) }\end{array}$ \\
\hline RBPEC & A2 & 1 & Santos (2018) \\
\hline \multicolumn{4}{|c|}{ Total de trabalhos: 17} \\
\hline
\end{tabular}

Fonte: elaborado pelos autores a partir dos dados da pesquisa (2018)

Os 17 trabalhos mostrados no Quadro 1 se referem àqueles que abordam propostas de uso da HFC implementadas em sala de aula. Observamos que os artigos com propostas implementadas se concentram nos periódicos voltados especificamente para o Ensino de Física e que $29 \%$ dos artigos selecionados foram publicados em 2018.

Compreendendo o período entre 1980 e meados de 2011, Teixeira, Greca e Freire Jr. (2012) analisaram 5 dos 6 periódicos apresentados no Quadro 1. Na ocasião, identificaram 13 artigos nacionais que utilizavam HFC em aulas de Física, o que, para eles, mostrava relativa escassez de trabalhos empíricos com foco na implementação de propostas em sala de aula. A partir desse dado, poderíamos ser induzidos a inferir que houve um aumento no número de publicações encontradas na investigação aqui apresentada; no entanto, na pesquisa conduzida por Schirmer e Sauerwein (2014), entre 2001 e 2010, nos mesmos periódicos mostrados no Quadro 1, os autores encontraram 18 artigos que abordavam temas da Física com intervenções didáticas implementadas e, naquele momento, também criticavam o reduzido número de publicações, dada a importância da área.

5 Classificação de acordo com o quadriênio 2013-2016 para a área de Ensino. Disponível em: https://sucupira.capes.gov.br/sucupira/public/index.xhtml. Acesso em: 17 jun. 2019. 
DOI: http://dx.doi.org/10.33238/ReBECEM.2019.v.3.n.3.23317

Avaliando que não houve considerável alteração no número de trabalhos publicados envolvendo a HFC e a sala de aula, conforme os resultados encontrados em pesquisas anteriores e nos dados mostrados no Quadro 1, a exortação de Teix eira, Greca e Freire Jr. continua atual. Para eles,

[...] essa área de pesquisa deve estar alerta para a necessidade de que sejam feitos maiores esforços para a realização de intervenções didáticas com uso de HFC no Ensino de Ciências e que tais intervenções sejam objetos de investigação, a fim de que se possa compreender melhor em situações reais de sala de aula qual a real contribuição que a HFC pode oferecer ao ensino e aprendizagem das ciências (TEIXEIRA; GRECA; FREIRE Jr., 2012, p. 18).

Vale destacar que a escassez deste tipo de publicação não é exclusividade do Ensino de Física, como nos mostra o trabalho de Barbosa e Aires (2018) em pesquisa envolvendo os periódicos da área de Ensino de Química.

A fim de ampliarmos as discussões, apresentamos por meio do Quadro 2 as características gerais dos trabalhos analisados, ressaltando, além do assunto abordado na proposta implementada, o nível de ensino em que ocorreu a intervenção, os recursos didáticos utilizados e a disponibilização pública de tais recursos (" $\mathrm{S}$ ” significa que está disponível, "N" não disponível e "P" parcialmente disponível).

Quadro 2: Caracterização geral dos trabalhos

\begin{tabular}{|c|c|c|c|c|}
\hline Autores & Tema & Nível & Recurso Didático & Disponível? \\
\hline $\begin{array}{c}\text { Rinaldi e Guerra } \\
(2011)\end{array}$ & $\begin{array}{c}\text { Ondas } \\
\text { Eletromagnéticas }\end{array}$ & EM & Experimento e texto paradidático & $\mathrm{S}$ \\
\hline $\begin{array}{c}\text { Silva, Santos e } \\
\text { Dias (2011) }\end{array}$ & $\begin{array}{c}\text { Física Moderna e } \\
\text { Contemporânea }\end{array}$ & EM & Texto secundário e experimento & $\mathrm{P}$ \\
\hline $\begin{array}{c}\text { Zanotello (2011) } \\
\text { Termodinâmica e }\end{array}$ & ES & Textos originais & $\mathrm{P}$ \\
\hline $\begin{array}{c}\text { Rodrigues, } \\
\text { Zimmermann e } \\
\text { Hartmann (2012) }\end{array}$ & $\begin{array}{c}\text { Gravitação } \\
\text { Universal }\end{array}$ & EM & Multimídia & $\mathrm{N}$ \\
\hline $\begin{array}{c}\text { Santos, Voelzke e } \\
\text { Araújo (2012) }\end{array}$ & Astronomia & EM & $\begin{array}{c}\text { Experimento histórico e textos } \\
\text { secundários }\end{array}$ & $\mathrm{S}$ \\
\hline $\begin{array}{c}\text { Morais e Guerra } \\
(2013)\end{array}$ & $\begin{array}{c}\text { Física Moderna e } \\
\text { Contemporânea }\end{array}$ & EM & $\begin{array}{c}\text { Multimídia, filmes, animações e } \\
\text { texto secundário }\end{array}$ & $\mathrm{P}$ \\
\hline $\begin{array}{c}\text { Raposo (2014) } \\
\text { Galileu Galilei }\end{array}$ & $\begin{array}{c}\text { EM/ } \\
\text { ES }\end{array}$ & $\begin{array}{c}\text { Textos secundários e originais e } \\
\text { experimento }\end{array}$ & $\mathrm{N}$ \\
\hline $\begin{array}{c}\text { Monteiro e Martins } \\
(2015)\end{array}$ & Inércia & ES & $\begin{array}{c}\text { Textos elaborados pelos próprios } \\
\text { autores }\end{array}$ & $\mathrm{P}$ \\
\hline $\begin{array}{c}\text { Raicik e Peduzzi } \\
(2015)\end{array}$ & Eletricidade & ES & $\begin{array}{c}\text { Artigos científicos, Textos } \\
\text { elaborados pelos próprios autores, } \\
\text { vídeos e experimento }\end{array}$ & $\mathrm{P}$ \\
\hline $\begin{array}{c}\text { Silva e Moraes } \\
(2015)\end{array}$ & Espectroscopia & EM & $\begin{array}{c}\text { Textos elaborados pelos próprios } \\
\text { autores e experimentos }\end{array}$ & $\mathrm{S}$ \\
\hline $\begin{array}{c}\text { Reis e Reis (2016) } \\
\text { Ferreira (2017) }\end{array}$ & Espaço-Tempo & EM & $\begin{array}{c}\text { Vídeos, animações, charges e } \\
\text { textos elaborados pelos próprios } \\
\text { autores }\end{array}$ & $\mathrm{P}$ \\
\hline
\end{tabular}


DOI: http://dx.doi.org/10.33238/ReBECEM.2019.v.3.n.3.23317

\begin{tabular}{|c|c|c|c|c|}
\hline $\begin{array}{c}\text { Arthury e } \\
\text { Terrazzan (2018) }\end{array}$ & Gravitação & EM & $\begin{array}{c}\text { Textos elaborados pelos próprios } \\
\text { autores, multimídia, vídeos e } \\
\text { trechos de LDs }\end{array}$ & $\mathrm{S}$ \\
\hline $\begin{array}{c}\text { Bagdonas, Zanetic } \\
\text { e Gurgel (2018) }\end{array}$ & Cosmologia & EM & Jogo didático & $\mathrm{S}$ \\
\hline $\begin{array}{c}\text { Hidalgo, Schivani } \\
\text { e Silva (2018) }\end{array}$ & $\begin{array}{c}\text { Pressão } \\
\text { Atmosférica }\end{array}$ & ES & $\begin{array}{c}\text { Textos originais, animações e } \\
\text { recortes de textos de LDs }\end{array}$ & $\mathrm{P}$ \\
\hline Santos (2018) & Modelos Atômicos & EM & Texto secundário e júri simulado & $\mathrm{S}$ \\
\hline $\begin{array}{c}\text { Vasconcelos e } \\
\text { Forato (2018) }\end{array}$ & Espectroscopia & ES & $\begin{array}{c}\text { Textos elaborados pelos próprios } \\
\text { autores }\end{array}$ & $\mathrm{S}$ \\
\hline
\end{tabular}

Fonte: elaborado pelos autores a partir dos dados da pesquisa (2018)

Conforme o Quadro 2, dos 17 trabalhos analisados, 11 foram implementados exclusivamente no Ensino Médio (EM) e 1 foi implementado tanto no EM quanto no Ensino Superior (ES). Além disso, dos artigos que relatam os resultados das atividades realizadas no ES, 5 se referem a cursos de formação de professores. Tais resultados são positivos, pois manifestam o interesse da comunidade de pesquisadores da área de Ensino em produzir propostas que subsidiem as práticas pedagógicas dos docentes na Educação Básica ou que instrumentalizem os professores em formação. Mesmo que tais ações não garantam a introdução dos conhecimentos vinculados à HFC na Educação Básica (MARTINS, 2007), conforme Hidalgo e Lorencini Jr. (2016), é fundamental que a inserção da HFC ocorra primeiramente nos cursos de formação de professores a fim de que os docentes tenham subsídios para trabalharem criticamente nesta perspectiva.

Diferentemente dos resultados encontrados por Teixeira, Greca, Freire Jr. (2012), em que os autores identificaram uma concentração de trabalhos tratando da Mecânica Clássica, observamos uma maior pluralidade temática no período investigado com trabalhos enfocando, inclusive, temas contemporâneos da Física.

A diversidade de recursos didáticos é outro aspecto interessante observado no Quadro 2. Apesar de haver uma predominância no uso de textos, algo também constatado por Schirmer e Sauerwein (2014) e por Barbosa e Aires (2018) - em pesquisa conduzida na área de Ensino de Química —, há propostas desenvolvidas que utilizam experimentos, livros didáticos (LDs), material multimídia, material paradidático, vídeos, animações e jogo didático. Tal diversidade é também bastante diferente dos resultados mostrados por Teixeira, Greca e Freire Jr. (2012), onde observaram que, por exceção de um, os demais trabalhos selecionados por eles utilizaram somente textos na intervenção didática de suas propostas.

Mesmo se tratarmos especificamente do uso de textos, conforme o Quadro 2, também notamos uma diversidade no tipo de texto que pode ser adotado em sala de aula: 
DOI: http://dx.doi.org/10.33238/ReBECEM.2019.v.3.n.3.23317

textos de fontes secundárias, textos de fontes primárias (originais), paradidáticos, artigos científicos e trechos de livros didáticos. Nos trabalhos consultados, este recurso, em geral, tem sido utilizado como apoio ao desenvolvimento da proposta, tal como em Silva, Santos e Dias (2011), Santos, Voelzke e Araújo (2012), Morais e Guerra (2013), Raposo (2014) e Santos (2018).

Observamos que há certa concentração na utilização de textos produzidos pelos próprios autores dos trabalhos analisados, o que, de acordo com Schirmer e Sauerwein (2014), pode mostrar “[...] que existe produção de material didático relacionado à HFC e que esses materiais são expostos a situações de sala de aula" (p. 67). Além disso, este tipo de recurso pode facilitar o acesso a materiais históricos de qualidade (ainda que, por não terem sido disponibilizados, nem todos possam ser avaliados) já que a obtenção de textos originais ou em língua estrangeira, por exemplo, nem sempre é algo simples.

Buscamos também identificar se os recursos didáticos mostrados no Quadro 2 foram disponibilizados ou indicados pelos pesquisadores. Nesta categoria, procuramos avaliar ainda a facilidade do acesso aos materiais. Os recursos didáticos utilizados nas propostas implementadas foram disponibilizados em apenas $47 \%$ dos artigos analisados (destacados pela letra "S" na última coluna do Quadro 2). Neste caso, a acessibilidade aos recursos está oportunizada por meio de material anexo à publicação, de links ativos e pela apresentação das referências de livros ou artigos científicos adotados.

Ainda em relação à disponibilização dos recursos, 35\% dos trabalhos apresentam parcialmente $(\mathrm{P})$ os recursos didáticos utilizados; alguns deles apenas indicam as referências de livros ou textos originais, mas que, por serem "antigos" ou em língua estrangeira, como os utilizados por Silva, Santos e Dias (2011), Zanotello (2011) e Hidalgo, Schivani e Silva (2018), não são, necessariamente, de fácil acesso — alguns destes autores traduziram parte ou a totalidade do texto adotado, mas somente Silva, Santos e Dias (2011) disponibilizou o trecho em questão; outros informam alguns materiais utilizados, principalmente os disponíveis na internet, mas falham ao não indicarem o restante dos recursos ou não detalhar a montagem experimental, como é caso de Silva, Santos e Dias (2011), Morais e Guerra (2013), Reis e Reis (2016) e Hidalgo, Schivani e Silva (2018). Há ainda trabalhos que, mesmo propondo atividades para o EM, fazem uso de equipamentos dificilmente disponíveis nas escolas, situação encontrada em Silva, Santos e Dias (2011). Tal ocorrência dificulta o aproveitamento da atividade em outros contextos escolares visto que, para os autores, a proposta é viável com a garantia do uso de equipamento específico (foram utilizados, por exemplo, um tubo de feixe 


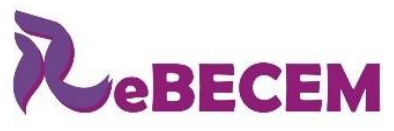

DOI: http://dx.doi.org/10.33238/ReBECEM.2019.v.3.n.3.23317
Revista Brasileira de Educação em

Ciências e Educação Matemática

colimado, um par de bobinas de Helmholtz, uma fonte de tensão de $600 \mathrm{~V}$-DC, entre outros dispositivos).

Os trabalhos que não disponibilizam nada a respeito dos recursos empregados, ou que o fazem de modo parcial, podem estar mais interessados em divulgar os resultados obtidos na implementação da proposta. É importante destacar que, obviamente, os pesquisadores não são obrigados a utilizar apenas materiais de fácil acesso ou disponibilizar publicamente suas produções intelectuais; contudo, acreditamos que tais ações podem contribuir com a inserção da HFC nas aulas de Física ou nos estudos daqueles interessados pela temática, pois, como apontado por Martins (2006; 2007) e Henke e Höttecke (2015), a falta de recursos didáticos pode se caracterizar como um dos principais obstáculos à utilização da HFC no ensino.

Por outro lado, é relevante ressaltar, conforme levantamento realizado por Teixeira, Greca e Freire Jr. (2012) e Schirmer e Sauerwein (2014), que existem inúmeras publicações relacionadas à HFC no Ensino de Ciências e no Ensino de Física que podem ser consultadas pelos interessados. Para ilustrar a possibilidade de encontrar artigos que envolvam a temática, tanto o CBEF quanto a RBEF possuem seções específicas que compreendem as publicações sobre História da Ciência.

Como será detalhado na sequência do trabalho, os recursos didáticos mostrados no Quadro 2 não refletem as estratégias empregadas pelos pesquisadores na abordagem da HFC em sala de aula. Alguns trabalhos abordaram os temas utilizando sequências didáticas (MORAIS; GUERRA, 2013; MONTEIRO; MARTINS; 2015; SILVA; MORAES, 2015; REIS; REIS, 2016), pedagogia de projetos (RAPOSO, 2014), módulo de ensino (RAICIK; PEDUZZI, 2015), aulas dialógicas e reflexivas (ZANOTELLO, 2011; MORAIS; GUERRA, 2013; ARTHURY; TERRAZZAN, 2018; HIDALGO; SCHIVANI; SILVA, 2018), atividades investigativas (PINTO; SILVA; FERREIRA, 2017) e interdisciplinares (SANTOS; VOELSKE; ARAÚJO, 2012), reedição das narrativas contidas em uma animação (HIDALGO; SCHIVANI; SILVA, 2018), produção de vídeos pelos alunos (REIS; REIS, 2016) e, de forma bastante interessante, por meio de um júri simulado (SANTOS, 2018). Todas as estratégias utilizadas são importantes por indicar diferentes possibilidades no uso da HFC em sala de aula. 
DOI: http://dx.doi.org/10.33238/ReBECEM.2019.v.3.n.3.23317

\subsection{Detalhamento dos resultados descritos nos trabalhos}

Visando identificar o interesse do pesquisador ao propor e implementar atividades envolvendo HFC, a partir da leitura dos trabalhos, elaboramos uma síntese dos objetivos definidos nas propostas implementadas em sala de aula (Quadro 3). Entre os objetivos identificados, estão: abordar/compreender conceitos relacionados ao tema (Conc.), contemplar aspectos da Natureza da Ciência $(\mathrm{NdC})$, avaliar a receptividade dos alunos (Rec.), avaliar a proposta didática ou os recursos utilizados (Prop.) e avaliar o envolvimento dos alunos (Env.). Destacamos que há categorias vinculadas aos artigos que não correspondem aos objetivos definidos pelos autores. Isso ocorre porque optamos por evidenciar também aspectos que surgem nas discussões dos resultados ou nas conclusões sobre as intervenções realizadas. Por isso, além dessa vinculação, acrescentamos no Quadro 3 uma coluna que visa indicar se o artigo apresentou carências, recomendações, dificuldades ou ressalvas na proposta implementada (Dif.). Adotamos x* para indicar as categorias que se referem aos objetivos definidos nos artigos e $\mathbf{x}$ para aquelas que aparecem nos resultados ou nas conclusões nos trabalhos analisados.

Quadro 3: Aspectos marcantes observados a partir dos objetivos, dos resultados e das conclusões

\begin{tabular}{|c|c|c|c|c|c|c|}
\hline Autores & Conc. & NdC & Rec. & Prop. & Env. & Dif. \\
\hline Rinaldi e Guerra (2011) & & $\mathbf{x}^{*}$ & & $\mathbf{x}$ & $\mathbf{x}$ & $\mathbf{x}$ \\
\hline Silva, Santos e Dias (2011) & $\mathbf{x}^{*}$ & & & & & \\
\hline Zanotello (2011) & $\mathbf{x}^{*}$ & $\mathbf{x}^{*}$ & $\mathbf{x}$ & $\mathbf{x}^{*}$ & $\mathbf{x}$ & \\
\hline Rodrigues, Zimmermann e Hartmann (2012) & $\mathbf{x}$ & $\mathbf{x}$ & $\mathbf{x}^{*}$ & $\mathbf{x}$ & $\mathbf{x}^{*}$ & \\
\hline Santos, Voelzke e Araújo (2012) & $\mathbf{X}^{*}$ & & & & $\mathbf{x}$ & \\
\hline Morais e Guerra (2013) & $\mathbf{x}^{*}$ & $\mathbf{x}$ & & $\mathbf{x}^{*}$ & $\mathbf{x}$ & $\mathbf{x}$ \\
\hline Raposo (2014) & & $\mathbf{X}^{*}$ & & & $\mathbf{x}$ & $\mathbf{x}$ \\
\hline Monteiro e Martins (2015) & $\mathbf{x}^{*}$ & $\mathbf{x}^{*}$ & & & & $\mathbf{x}$ \\
\hline Raicik e Peduzzi (2015) & $\mathbf{x}$ & $\mathbf{x}^{*}$ & $\mathbf{x}$ & $\mathbf{x}^{*}$ & $\mathbf{x}$ & \\
\hline Silva e Moraes (2015) & $\mathbf{x}^{*}$ & $\mathbf{x}$ & & $\mathbf{x}$ & $\mathbf{x}$ & $\mathbf{x}$ \\
\hline Reis e Reis (2016) & $\mathbf{x}$ & $\mathbf{x}^{*}$ & & $\mathbf{x}$ & & $\mathbf{x}$ \\
\hline Pinto, Silva e Ferreira (2017) & $\mathbf{x}^{*}$ & $\mathbf{x}$ & & & $\mathbf{x}$ & \\
\hline Arthury e Terrazzan (2018) & $\mathbf{x}$ & $\mathbf{x}^{*}$ & $\mathbf{x}$ & $\mathbf{x}$ & & $\mathbf{x}$ \\
\hline Bagdonas, Zanetic e Gurgel (2018) & $\mathbf{x}$ & $\mathbf{x}^{*}$ & & & & \\
\hline Hidalgo, Schivani e Silva (2018) & & $\mathbf{x}$ & & $\mathbf{x}^{*}$ & $\mathbf{x}$ & \\
\hline Santos (2018) & $\mathbf{X}^{*}$ & $\mathbf{x}^{*}$ & & & $\mathbf{x}$ & $\mathbf{x}$ \\
\hline Vasconcelos e Forato (2018) & & $\mathbf{x}^{*}$ & & & & \\
\hline
\end{tabular}

Fonte: Elaborado pelos autores a partir dos dados da pesquisa (2018)

Os dados sistematizados no Quadro 3 correspondem a diversas informações que visam facilitar as discussões quanto às intenções e as possíveis contribuições proporcionadas por cada proposta à área. 
DOI: http://dx.doi.org/10.33238/ReBECEM.2019.v.3.n.3.23317

Ao analisarmos os dados apresentados, observamos que o uso da HFC para a abordagem de conceitos físicos (Conc.), considerada pela literatura como positiva para uma abordagem integrada aos conceitos científicos (HIDALGO; LORENCINI Jr., 2016), é algo que ganha destaque nas propostas implementadas, sendo um dos objetivos em $47 \%$ dos trabalhos. Vale ressaltar que, com exceção de Monteiro e Martins (2015) e Santos, Voelske e Araújo (2012), os artigos não avaliaram, por meio de algum instrumento, a aprendizagem dos alunos quanto aos conceitos tratados durante a intervenção. No entanto, os relatos são unânimes em apontar positivamente para a contribuição da HFC utilizada na compreensão dos conceitos envolvidos no tema abordado.

A reflexão sobre aspectos relacionados à $\mathrm{NdC}$ foi alvo direto de $59 \%$ dos trabalhos analisados. Apesar de observarem algumas dificuldades (ZANOTELLO, 2011) e a permanência de visões ingênuas ou difíceis de serem alteradas (BAGDONAS; ZANETIC; GURGEL, 2018), os autores constataram avanços nas discussões efetuadas pelos alunos participantes das atividades. Ressaltando resultados satisfatórios para o objetivo, Rinaldi e Guerra (2011) e Arthury e Terrazzan (2018) indicam, respectivamente, que a proposta desenvolvida pode se estabelecer como um caminho para abordar a $\mathrm{NdC}$ e mobilizar elementos dessa natureza em aulas de Física. Sem ter a intenção de “[...] mudar a forma de pensar dos alunos [...]”, Reis e Reis (2016, p. 771) destacam que os episódios históricos utilizados e as atividades didáticas desenvolvidas permitiram, entre outras coisas, problematizar o processo de construção dos conceitos abordados e suas condições transitórias e controversas, contribuindo para que os alunos compreendessem a ciência como desenvolvida por homens imersos em crenças e valores, e não como algo pronto e acabado.

As duas primeiras categorias - Conc. e $\mathrm{NdC}$ - juntamente com a avaliação da receptividade dos alunos (Rec.), foram as únicas também observadas por Teixeira, Greca e Freire Jr. (2012). Mesmo que nestas categorias os resultados da nossa análise tenham sido próximos aos encontrados por eles, vale destacar que, dos trabalhos que objetivavam abordar aspectos sobre a $\mathrm{NdC}$, os autores identificaram que $86 \%$ deles foram implementados no Ensino Superior ; já em nossa análise, 60\% das propostas com este objetivo foram desenvolvidas no Ensino Médio. Como já indicamos, isso pode representar um maior interesse dos pesquisadores em desenvolver propostas para a Educação Básica. Alegando maior facilidade em promover mudanças de concepções sobre a NdC em estudantes da Educação Básica, Teixeira, Greca e Freire Jr. (2012) 


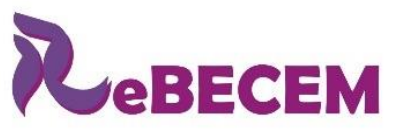

Revista Brasileira de Educação em

Ciências e Educação Matemática

DOI: http://dx.doi.org/10.33238/ReBECEM.2019.v.3.n.3.23317

acreditavam ser necessário desenvolver mais intervenções que visassem propiciar concepções críticas sobre as ciências aos estudantes deste nível de ensino.

Conforme o Quadro 3, apenas o trabalho de Rodrigues, Zimmermann e Hartmann (2012) se propôs a avaliar, como objetivo central do trabalho, a receptividade (Rec.) e o envolvimento (Env.) dos sujeitos participantes na implementação da proposta. Por meio de entrevistas, os autores observaram que, apesar de bem aceita, a multimídia desenvolvida sofreu resistência inicial devido à mudança ao estilo de aula que os alunos estavam habituados. Reiteraram também que houve bom envolvimento dos estudantes ao longo da intervenção e que o recurso utilizado (a multimídia, composta por fotos, filmes, textos, animações, entre outros) permitiu tornar as aulas mais dinâmicas e interessantes para os alunos. Por outro lado, relataram surpresa quando alguns estudantes mencionaram que preferiam continuar com aulas "tradicionais" devido à preocupação com os conteúdos do vestibular.

Zanotello (2011), Raicik e Peduzzi (2015) e Arthury e Terrazan (2018), utilizando questionários, também avaliaram a receptividade da proposta pelos participantes e constataram satisfatória aceitação.

Sobre o envolvimento (Env.) dos participantes, em todos os trabalhos enquadrados nesta categoria, há relatos que indicam boa participação dos alunos, mas, embora houvesse a predominância do uso de textos, como mostrado no Quadro 2, Rodrigues, Zimmermann e Hartmann (2012), Silva e Moraes (2015) e Arthury e Terrazan (2018) constataram que o uso de vídeos, e outros recursos dinâmicos e diferenciados, potencializou a proposta e impactou positivamente no interesse dos participantes. No entanto, conforme observado por Morais e Guerra (2013) e Reis e Reis (2016), há de se tomar cuidado na utilização de tais recursos, pois podem possuir erros históricos, além de reforçar características indesejáveis sobre a $\mathrm{NdC}$. Por isso, é recomendado a utilização de textos de apoio como subsídio e confronto das ideias apresentadas (REIS; REIS, 2016).

A avaliação crítica das propostas implementadas (Prop.), mesmo que não como objetivo principal, foi discutida em 53\% dos trabalhos. Neste aspecto, após análise da intervenção realizada, Silva e Moraes (2015) argumentam que a abordagem histórica não foi fundamental para atingir o objetivo proposto — associação com o conteúdo —, mas que isso permitiu destacar pontos importantes sobre o desenvolvimento científico do tema trabalhado, além de outros conceitos envolvidos. Reis e Reis (2016, p. 759), também foram ponderados e, mesmo alegando "certo sucesso" nas atividades realizadas, elencaram diversos pontos que precisam ser revistos caso a proposta seja reaplicada. 
DOI: http://dx.doi.org/10.33238/ReBECEM.2019.v.3.n.3.23317

O módulo desenvolvido e avaliado por Raicik e Peduzzi (2015) apresentou resultados satisfatórios, mostrando, segundo eles, ser um material útil para discutir, histórica e filosoficamente, os conceitos iniciais do tema abordado. Na avaliação de Hidalgo, Schivani e Silva (2018), a proposta implementada por eles apresentou resultados surpreendentes, principalmente pelo nível de aprofundamento das análises dos alunos; quanto ao recurso didático empregado (um Objeto Virtual de Aprendizagem), que foi reeditado pelos estudantes, os autores identificaram diversos problemas relacionados à $\mathrm{NdC}$ e erros históricos.

Mesmo não detalhando os resultados das avaliações de todas as propostas, observamos que todos os autores que se enquadraram na categoria "Prop." manifestaram satisfação com os resultados da implementação.

Acreditamos que não há intervenções didáticas infalíveis, o que nos levou a esperar que todos os trabalhos analisados estivessem presentes na última categoria do Quadro 3. No entanto, mesmo que grande parte das informações tenham sido abordadas superficialmente, somente $47 \%$ dos trabalhos mostrados no quadro apresentaram observações para a proposta implementada, tais como carências, recomendações, dificuldades ou ressalvas (Dif.). A presença destas informações, as quais consideramos importantes para uma possível reaplicação, podem indicar uma reflexão crítica dos autores entre o que foi proposto e o implementado.

Avançando na análise, ao contrapormos os dados da categoria citada acima com aqueles que se referem à disponibilidade das atividades desenvolvidas (Quadro 2), observamos que menos da metade desses autores viabilizaram a reprodução do que foi divulgado. No entanto, ainda assim, abordaremos os principais pontos levantados em alguns dos trabalhos concernentes a esta categoria.

O trabalho de Rinaldi e Guerra (2011) está entre aqueles que apresentaram ressalvas para o sucesso das atividades desenvolvidas. Para eles, esse resultado se vincula ao fato de que a implementação ocorreu em um grupo pequeno de apenas 7 alunos e por terem obtido o apoio de profissional externo à escola e ao projeto desenvolvido durante a execução da atividade.

Há ainda relatos de dificuldades vinculadas aos alunos participantes da intervenção. Na implementação conduzida por Raposo (2014), os alunos demonstraram dificuldades com a matemática envolvida em uma atividade demonstrativa. Enquanto Silva e Moraes (2015) reclamaram que os alunos não liam previamente os textos solicitados, o que os forçaram a uma mudança de estratégia. Morais e Guerra (2013), 
DOI: http://dx.doi.org/10.33238/ReBECEM.2019.v.3.n.3.23317

Monteiro e Martins (2015) e Arthury e Terrazzan (2018) queixaram-se que a ausência de hábito de leitura nos estudantes comprometeu o andamento das atividades, impactando, inclusive, no entendimento dos textos.

O tempo didático insuficiente para o planejamento ou execução da intervenção foi um problema encontrado por Morais e Guerra (2013), Monteiro e Martins (2015), Silva e Moraes (2015) e Reis e Reis (2016). Neste caso, os autores recomendam um tempo maior para a execução da proposta.

Como podemos observar, algumas dificuldades encontradas pelos pesquisadores são similares àquelas já manifestadas na literatura. Em pesquisa conduzida por Martins (2007) verificou-se que, entre outros fatores, o tempo necessário para a abordagem, a falta de hábito de leitura dos estudantes, o apego a aulas "tradicionais", o planejamento e a execução das atividades e a possível monotonia das aulas, se figuram como obstáculos à inserção da HFC na Educação Básica. Contudo, ressaltamos que, ao apresentarem suas análises críticas para a implementação realizada, os autores analisados neste trabalho (Quadro 3) relatam experiências positivas e de superação de alguns desses obstáculos.

Mesmo que às vezes de maneira rasa ou indireta, alguns autores, como Silva e Moraes (2015), Reis e Reis (2016), Santos (2018) e Arthury e Terrazzan (2018), elencam recomendações para uma aplicação futura da intervenção proposta. Destacamos a recomendação de Arthury e Terrazzan (2018) que, ao indicarem que o envolvimento dos alunos, em uma mesma atividade, diminuía com o tempo, sugerem que sejam implementadas propostas com tempo mais flexível, de modo a permitir o fracionamento de algumas atividades. Já Zanotello (2011) e Pinto, Silva e Ferreira (2017) afirmam que a mediação do professor é fundamental para o sucesso da intervenção didática.

Na hipótese de reaplicar as intervenções aqui discutidas ou de elaborar atividades próprias envolvendo a abordagem da HFC, além das observações apontadas nos trabalhos analisados, recomendamos que os professores façam a leitura do artigo de Forato, Pietrocola e Martins (2011). Neste trabalho os autores apresentam alguns desafios a serem enfrentados, além de alguns conflitos e dilemas, para uma adequada abordagem da HFC no ambiente escolar.

Ao expormos a ideia de se permitir a reaplicação da proposta, não queremos dizer que ela deva ocorrer tal como definido por seus desenvolvedores; afinal, cada escola e sala de aula são únicas, impedindo, assim, uma reprodução fiel com resultados idênticos. Entretanto, se todas as propostas analisadas neste trabalho se dessem baseadas em um recurso didático não disponibilizado, os professores interessados nem sequer teriam a 
DOI: http://dx.doi.org/10.33238/ReBECEM.2019.v.3.n.3.23317

possibilidade de adaptar a intervenção para o seu contexto. Neste sentido, Forato, Pietrocola e Martins (2011) afirmam ser importante que, além de haver mais publicações envolvendo o uso da HFC no âmbito escolar, o resultado dessas pesquisas (e, acrescentamos, os recursos didáticos desenvolvidos e utilizados) sejam acessíveis aos professores.

Aos professores da Educação Básica, salientamos nossa concordância com Arthury e Terrazzan (2018) de que as ações ou recursos desenvolvidos e divulgados em cada artigo possam ser "possíveis norteadores para se pensar atividades correlatas [...] um ponto de partida fundamentado para outros caminhos, outras possibilidades" (p. 20).

\section{Considerações finais}

Diversos autores afirmam aspectos positivos vinculados à utilização da HFC no ensino de Física. Entretanto, seu uso efetivo em sala de aula tem sido dificultado por meio de vários obstáculos, como o pouco tempo para planejamento das aulas, ausência de formação de professores nesta perspectiva e, principalmente, a falta de materiais didáticos adequados. Assim, considerando tais problemáticas, e com base em trabalhos similares, procuramos apresentar os resultados de um levantamento bibliográfico que buscou por intervenções didáticas realizadas em sala de aula envolvendo a HFC.

Em nossa busca, encontramos 17 artigos que abordam diferentes temáticas no uso da HFC, inclusive tópicos de Física Moderna e Contemporânea, e que, apesar de haver uma concentração na utilização de textos, exploram distintos recursos didáticos em sua implementação. Além disso, de modo positivo e diferentemente de resultados anteriores, encontramos uma tendência de pesquisas focadas na Educação Básica.

Apesar de alguns dos trabalhos analisados terem apresentado dificuldades semelhantes às reportadas na literatura, diversos deles salientaram observações críticas que podem servir de orientação aos interessados em reaplicar suas propostas. Além disso, há de se considerar que os trabalhos mencionaram resultados satisfatórios quanto a participação e o envolvimento dos alunos nas atividades, a melhoria na aprendizagem de conceitos físicos e na compreensão de aspectos relativos à $\mathrm{NdC}$, entre outros. Fatores estes que podem servir de motivação para que os professores se interessem por tal abordagem em suas aulas.

Por apresentarmos aspectos relevantes a serem considerados pelos autores, acreditamos que a realização deste levantamento possa contribuir com novas pesquisas 


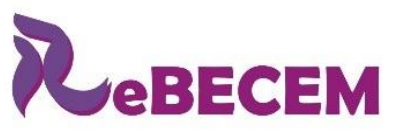

Revista Brasileira de Educação em
Ciências e Educação Matemática
ISSN 2594-9179

DOI: http://dx.doi.org/10.33238/ReBECEM.2019.v.3.n.3.23317

que visam propor e implementar intervenções didáticas sobre a HFC. Além disso, ao professor interessado em abordar a HFC em suas aulas, o presente estudo pode servir como um indicativo de propostas didáticas que tenham sido "testadas" em situação de sala de aula, podendo, assim, adaptá-las ao seu contexto escolar.

Por último, reforçamos nosso entendimento de que, no intuito de reduzir a escassez de material de apoio adequado às aulas de Física, quando da divulgação dos resultados em intervenções envolvendo a HFC e a sala de aula, deve haver uma maior tentativa da comunidade científica em disponibilizar integralmente os recursos utilizados ou elaborados.

\section{Referências}

ARTHURY, L. H. M.; TERRAZZAN, E. A. A Natureza da Ciência na escola por meio de um material didático sobre a Gravitação. Revista Brasileira de Ensino de Física, São Paulo, v. 40, n. 3, p. 1-21, 2018.

BRASIL. Secretaria da Educação Básica. PCN + Ensino médio: orientações educacionais complementares aos Parâmetros Curriculares Nacionais - Ciências da Natureza, Matemática e suas Tecnologias. Brasília, 2002. Disponível em:

http://portal.mec.gov.br/seb/arquivos/pdf/CienciasNatureza.pdf. Acesso em: 24 set. 2019.

BAGDONAS, A.; ZANETIC, J.; GURGEL, I. O maior erro de Einstein? Debatendo o papel dos erros na ciência através de um jogo didático sobre cosmologia. Caderno Brasileiro de Ensino de Física, Florianópolis, v. 35, n. 1, p. 97-117, 2018.

BARBOSA, F. T.; AIRES, J. A. História e Filosofia da Ciência em periódicos nacionais: um referencial para os professores de Química. História da Ciência e Ensino: construindo interfaces, São Paulo, v. 17, p. 3-21, 2018.

COUTINHO, C. P. Metodologia de investigação em Ciência Sociais e Humana: teoria e prática. 2. ed. Coimbra: Edições Almedina S.A., 2015.

FERREIRA, J. M. H.; MARTINS, A. F. P. Avaliando a inserção da temática natureza da ciência na disciplina de história e filosofia da ciência para graduados em Física na UFRN. In: PEDUZZI, L. O. Q.; MARTINS, A. F. P.; FERREIRA, J. M. H. (org.). Temas de História e Filosofia da Ciência no Ensino. Natal, RN: EDUFRN, 2012. p. 155-181.

FORATO, T. C. M.; MARTINS, R. A.; PIETROCOLA, M. Enfrentando obstáculos na transposição didática da história da ciência para a sala de aula. In: PEDUZZI, L. O. Q.; MARTINS, A. F. P.; FERREIRA, J. M. H. (org.). Temas de História e Filosofia da Ciência no Ensino. Natal, RN: EDUFRN, 2012. p. 123-155.

FORATO, T. C. M.; PIETROCOLA, M.; MARTINS, R. A. Historiografia e Natureza da Ciência em sala de aula. Caderno Brasileiro de Ensino de Física, Florianópolis, v. 28, n. 1, p. 27-59, 2011. 
DOI: http://dx.doi.org/10.33238/ReBECEM.2019.v.3.n.3.23317

HIDALGO, M. R.; LORENCINI Jr., Â. Reflexões sobre a inserção da História e Filosofia da Ciência no Ensino de Ciências. História da Ciência e Ensino: construindo interfaces, São Paulo, v. 14, p. 19-38, 2016.

HIDALGO, J. M.; SCHIVANI, M.; SILVA, M. M. História e Filosofia da Ciência na formação docente: trabalhando com animações digitais. Caderno Brasileiro de Ensino de Física, Florianópolis, v. 35, n. 3, p. 805-850, 2018.

HENKE, A.; HÖTTECKE, D. Physics Teachers' Challenges in Using History and Philosophy of Science in Teaching. Science \& Education, Dordrecht, v. 24, n. 4, p. 349-385, 2015.

HÖTTECKE, D.; SILVA, C. C. Why Implementing History and Philosophy in School Science Education is a Challenge: An Analysis of Obstacles. Science \& Education, Dordrecht, v. 20, n. 3-4, p. 293-316, 2011.

MARTINS, R. A. História da Ciência e seus usos na educação. In: SILVA, C. C. (org.). Estudos de História e Filosofia das Ciências: subsídios para aplicação no Ensino. São Paulo: Editora Livraria da Física, 2006. p. XXI-XXIV.

MARTINS, A. F. História e filosofia da ciência no ensino: há muitas pedras nesse caminho. Caderno Brasileiro de Ensino de Física, Florianópolis, v. 24, n. 1, p. 112-131, 2007.

MATTHEWS, M. R. A role for history and philosophy in science teaching. Educational Philosophy and Theory, Randwick, v. 20, n. 2, p. 67-81, 1988.

MATTHEWS, M. R. História, filosofia e ensino de ciências: a tendência atual de reaproximação. Caderno Catarinense de Ensino de Física, Florianópolis, v. 12, n. 3, p. 164214, 1995.

MATTHEWS, M. R. History of science in the curriculum and in classrooms. In: MATTHEWS, M. R. (org.). Science Teaching: the contribution of history and philosophy of science. 2. ed. New York: Routledge, 2015. p. 106-142.

MCCOMAS, W. Uma proposta de classificação para os tipos de Aplicação da história da ciência na formação Científica: implicações para a pesquisa e Desenvolvimento. In: SILVA, C. C.; PRESTES, M. E. B. (org.). Aprendendo ciência e sobre sua natureza: abordagens históricas e filosóficas. São Carlos, SP: Tipographia Editora Expressa, 2013. p. 425-488.

MONTEIRO, M. M.; MARTINS, A. F. P. História da ciência na sala de aula: Uma sequência didática sobre o conceito de inércia. Revista Brasileira de Ensino de Física, São Paulo, v. 37, n. 4. p. 4501-1-4501-9. 2015.

MORAIS, A.; GUERRA, A. História e a filosofia da ciência: caminhos para a inserção de temas física moderna no estudo de energia na primeira série do Ensino Médio. Revista Brasileira de Ensino de Física, São Paulo, v. 35, n. 1, p. 1502-1-1502-9, 2013.

PINTO, J. A. F.; SILVA, A. P. B.; FERREIRA, É. J. B. Laboratório desafiador e história da ciência: um relato de experiência com o experimento de Oersted. Caderno Brasileiro de Ensino de Física, Florianópolis, v. 34, n. 1, p. 176-196, 2017.

RAPOSO, W. L. História e Filosofia da Ciência na Licenciatura em Física: uma proposta de ensino através da pedagogia de projetos. Caderno Brasileiro de Ensino de Física, Florianópolis, v. 31, n. 3, p. 722-738, 2014. 
DOI: http://dx.doi.org/10.33238/ReBECEM.2019.v.3.n.3.23317

RAICIK, A. C.; PEDUZZI, L. O. Q. Potencialidades e limitações de um módulo de ensino: uma discussão histórico-filosófica dos estudos de Gray e Du Fay. Investigação em Ensino de Ciências, Porto Alegre, v. 20, n. 2, p. 138-160, 2015.

RINALDI, E.; GUERRA, A. História da ciência e o uso da instrumentação: construção de um transmissor de voz como estratégia de ensino. Caderno Brasileiro de Ensino de Física, Florianópolis, v. 28, n. 3, p. 653-675, 2011.

REIS, U. V.; REIS, J. C. Os conceitos de espaço e de tempo como protagonistas no ensino de Física: um relato sobre uma sequência didática com abordagem histórico-filosófica. Caderno Brasileiro de Ensino de Física, Florianópolis, v. 33, n. 3, p. 744-778, 2016.

RODRIGUES, E. V.; ZIMMERMANN, E.; HARTMANN, Â. M. Lei da gravitação universal e os satélites: uma abordagem histórico-temática usando multimídia. Ciência \& Educação, Bauru, v. 18, n. 3, p. 503-525, 2012.

SANTOS, A. J. J.; VOELZKE, M. R.; ARAÚJO, M. S. T. O Projeto Eratóstenes: a reprodução de um experimento histórico como recurso para a inserção de conceitos da Astronomia no Ensino Médio. Caderno Brasileiro de Ensino de Física, Florianópolis, v. 29, n. 3, p. 1137 1174, 2012.

SANTOS, M. Uso da História da Ciência para Favorecer a Compreensão de Estudantes do Ensino Médio sobre Ciência. Revista Brasileira de Pesquisa em Educação em Ciências, Belo Horizonte, v. 18, n. 2, p. 641-668, 2018.

SCHIRMER, S. B. R.; SAUERWEIN, I. P. S. Recursos Didáticos e História e Filosofia da Ciência em sala de aula: uma análise em periódicos de ensino nacionais. Revista Brasileira de Pesquisa em Educação em Ciências, Belo Horizonte, v. 14, n. 3, p. 61-77, 2014.

SILVA, L. C. M.; SANTOS, W. M. S.; DIAS, P. M. C. A carga específica do elétron: Um enfoque histórico e experimental. Revista Brasileira de Ensino de Física, v. 33, n. 1, p. 16011607, 2011.

SILVA, H. R. A.; MORAES, A. O estudo da espectroscopia no ensino médio através de uma abordagem histórico-filosófica: possibilidade de interseção entre as disciplinas de Química e Física. Caderno Brasileiro de Ensino de Física, Florianópolis, v. 32, n. 2, p. 378-406, 2015.

TEIXEIRA, E. S.; GRECA, I. M.; FREIRE Jr. O. Uma revisão sistemática das pesquisas publicadas no Brasil sobre o uso didático de história e filosofia da ciência no ensino de Física. In: PEDUZZI, L. O. Q.; MARTINS, A. F. P.; FERREIRA, J. M. H. (org.). Temas de História e Filosofia da Ciência no Ensino. Natal, RN: EDUFRN, 2012. p. 9-40.

VASCONCELOS, S. S.; FORATO, T. M. Niels Bohr, espectroscopia e alguns modelos atômicos no começo do século XX: um episódio histórico para a formação de professores. Caderno Brasileiro de Ensino de Física, Florianópolis, v. 35, n. 3, p. 851-887, 2018.

ZANOTELLO, M. Leitura de textos originais de cientistas por estudantes do ensino superior. Ciência \& Educação, Bauru, v. 7, n. 4, p. 987-1013, 2011.

Recebido em: 24 de setembro de 2019.

Aceito em: 02 de dezembro de 2019. 